\title{
Effect of Particle Concentration, Sealing Condition and Breathing Rate on Total Inward Leakage for N95 Filtering Facepiece Respirators
}

\author{
Taoreed T. Lawal \\ ttlawal@mix.wvu.edu
}

Follow this and additional works at: https://researchrepository.wvu.edu/etd

Part of the Other Operations Research, Systems Engineering and Industrial Engineering Commons

\author{
Recommended Citation \\ Lawal, Taoreed T., "Effect of Particle Concentration, Sealing Condition and Breathing Rate on Total Inward \\ Leakage for N95 Filtering Facepiece Respirators" (2020). Graduate Theses, Dissertations, and Problem \\ Reports. 7890. \\ https://researchrepository.wvu.edu/etd/7890
}

This Thesis is protected by copyright and/or related rights. It has been brought to you by the The Research Repository @ WVU with permission from the rights-holder(s). You are free to use this Thesis in any way that is permitted by the copyright and related rights legislation that applies to your use. For other uses you must obtain permission from the rights-holder(s) directly, unless additional rights are indicated by a Creative Commons license in the record and/ or on the work itself. This Thesis has been accepted for inclusion in WVU Graduate Theses, Dissertations, and Problem Reports collection by an authorized administrator of The Research Repository @ WVU. For more information, please contact researchrepository@mail.wvu.edu. 
Effect of Particle Concentration, Sealing Condition and Breathing Rate on Total Inward Leakage for N95 Filtering Facepiece Respirators

\author{
Taoreed T. Lawal \\ Thesis submitted to the \\ Statler College of Engineering and Mineral Resources \\ at West Virginia University \\ in partial fulfillment of the requirements for the degree of \\ Master of Science in \\ Industrial Hygiene
}

Committee Members

Warren Myers, Ph.D., Chair

Michael McCawley, Ph.D.

Ziqing Zhuang, Ph.D.

Department of Industrial and Management Systems Engineering

Morgantown, West Virginia

2020

Keywords: Total inward leakage, N95 FFRs, Respirators, Sealing Conditions, Breathing Rate,

Concentration Level

Copyright 2020: Taoreed Taiwo Lawal 


\title{
ABSTRACT \\ Effect of Particle Concentration, Sealing Condition and Breathing Rate on Total Inward Leakage for N95 Filtering Facepiece Respirators
}

\author{
Taoreed T. Lawal
}

Several researchers have considered the relationship between total inward leakage (TIL) and other parameters such as sealing condition, particle concentration, type of particulate material breathing parameters, etc., however, there is dearth of information on the effects of varying particle concentration on the penetration efficiency of filtering facepiece respirators (FFRs), hence, this study aims to study the effect of varying $\mathrm{NaCl}$ particle concentration, sealing condition and breathing rate on the TIL as a result of the filtering efficiency of the filters.

To achieve this, we followed the sampling procedure used by He et al., 2014. Four different sealing conditions (SCs) namely; fully sealed, fully opened, chin sealed, and cheek \& chin sealed was used. $\mathrm{NaCl}$ aerosol particle was used at varying concentration levels of 100,000 (100K), 200,000 $(200 \mathrm{~K})$ and 400,000 (400K). Also, we used mean inspiratory flow rates of 15LPM, 30LPM, 55LPM and 85LPM which we refer to as breathing rate throughout this study. Visual presentation of result was done with Python 3.8 and data analysis was carried out using R version 3.6.0 (201904-26). The statistical model statement follows the equation TILsC $=\beta o+\beta_{1} B+\beta_{2} C+\beta_{3} B C+£$. where $\mathrm{B}$ is the breathing rate at the $4 \mathrm{MIF}, 15,30,55$, and 85 ; $\mathrm{C}$ is concentration and $\mathrm{BC}$ is the interaction between Breathing flow rate and the concentration. TILsc is the total inward leakage at the different sealing conditions

The result shows that the variables have effect on the TIL for both fully opened and cheek and chin sealed condition with or without interaction between the variables at 0.05 confidence level. For fully sealed and chin sealed condition, the variables have no significant effect on the mean TIL response when interaction between variables was considered and when interaction between variables was not considered.

In conclusion, there is statistically significance difference for mean TIL response with the change in sealing conditions, varying concentrations of $\mathrm{NaCl}$ particle and breathing rates.

This study showed that in studying the effect of varying $\mathrm{NaCl}$ particle concentration, sealing conditions and breathing rate on the TIL, it is only under both fully opened and cheek and chin sealed conditions that the mean TIL response is significantly affected by the factors in consideration. Hence, workers should not expose their nose region at any time to prevent exposure. 


\section{CONTENTS}

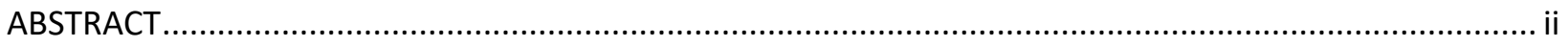

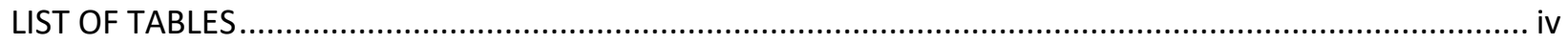

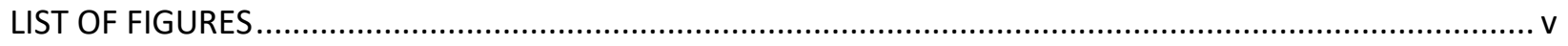

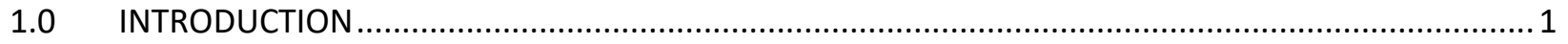

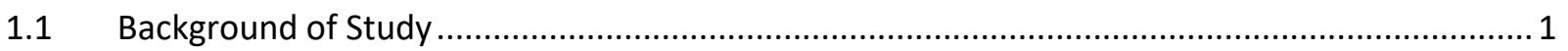

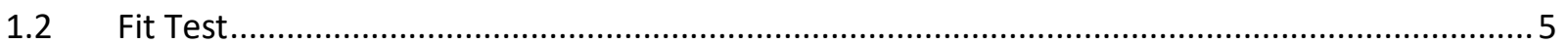

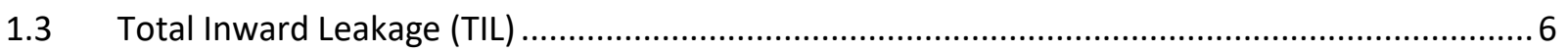

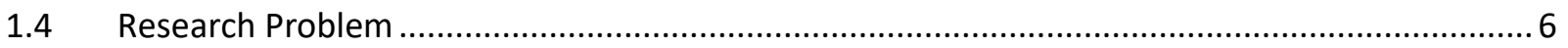

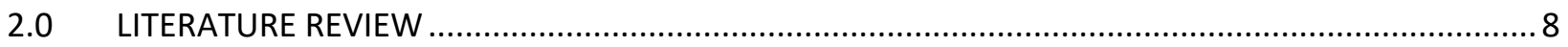

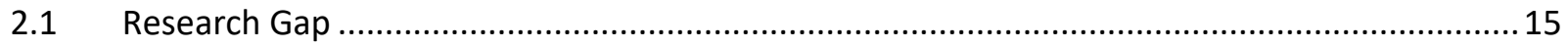

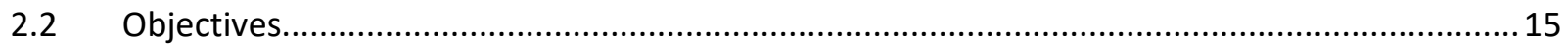

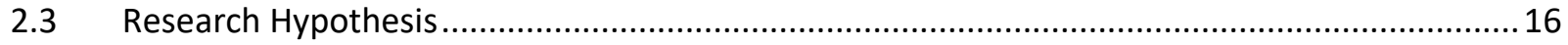

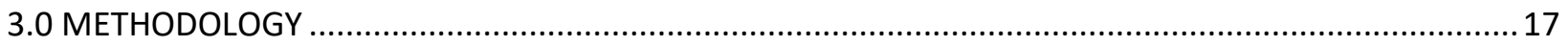

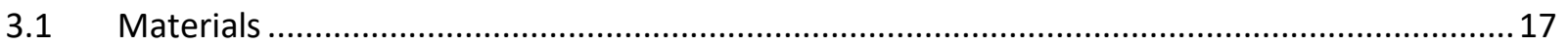

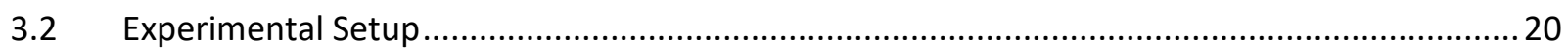

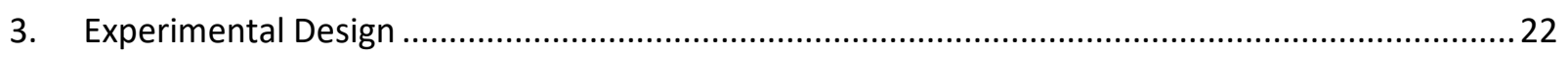

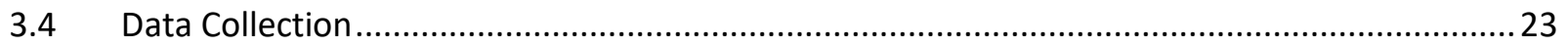

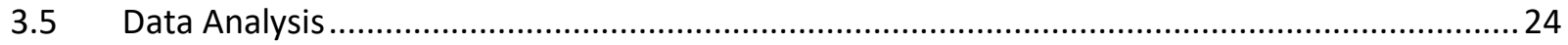

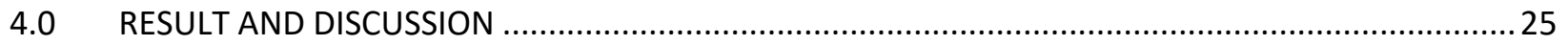

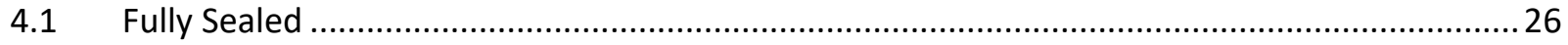

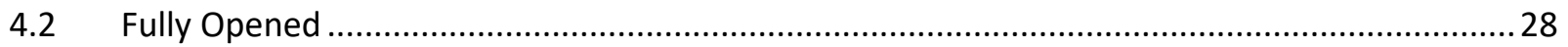

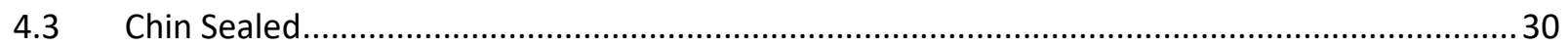

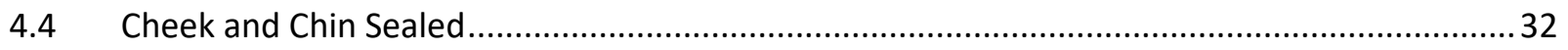

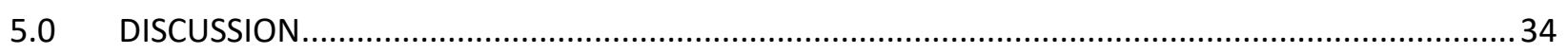

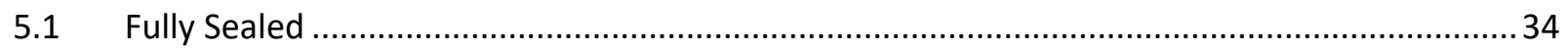

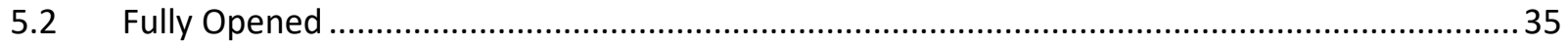

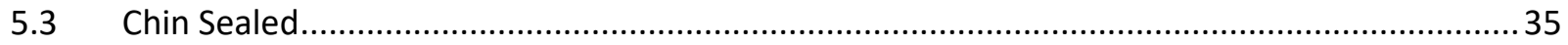

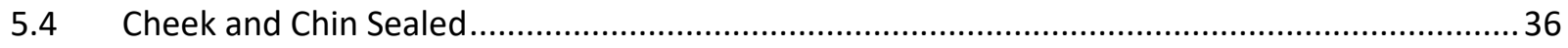

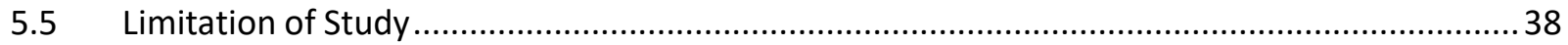

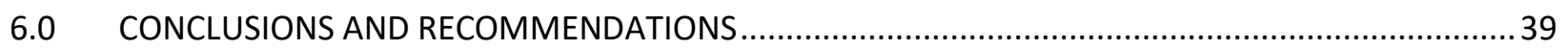

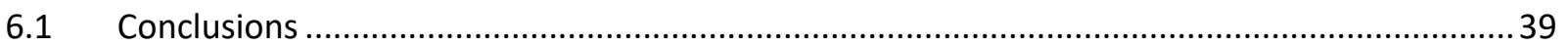

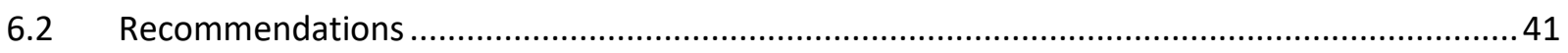




\section{LIST OF TABLES}

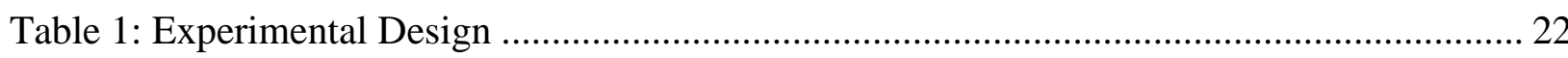

Table 2: Analysis of Variance Table Without Interaction for Fully Sealed Condition ............... 27

Table 3: Analysis of Variance Table for Fully Sealed Condition with interaction .................... 27

Table 4: Analysis of Variance for Fully Opened Condition without Interaction ...................... 29

Table 5: Analysis of Variance for Fully Opened Condition with Interaction........................... 29

Table 6: Analysis of Variance Table for Chin Sealed Condition without Interaction ................. 31

Table 7: Analysis of Variance Table for Chin Sealed Condition with Interaction ..................... 31

Table 8: Analysis of Variance for Cheek and Chin Sealed Condition without Interaction .......... 33

Table 9: Analysis of Variance for Cheek and Chin Sealed Condition with Interaction .............. 33 


\section{LIST OF FIGURES}

Figure 1: Moldex 2200N95 Series (Non Exhalative Valve) .................................................... 17

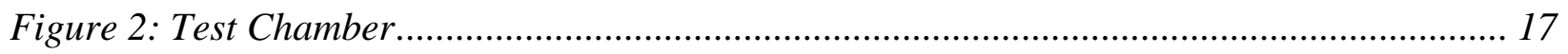

Figure 3: Experimental Setup with donned Manikin ......................................................... 18

Figure 4: Needle used to induce Artificial Leak ........................................................................ 18

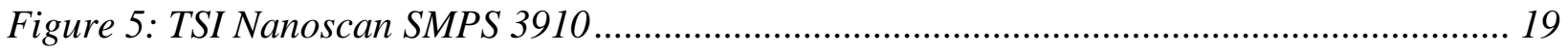

Figure 6: Model 8026 Particle Generator........................................................................... 19

Figure 7:Comparing Breathing Rate and TIL for different Clevels under fully Sealed Condition

Figure 8: Comparing Breathing Rate and TIL at Different Clevels for Fully Opened Condition 28

Figure 9: Comparing Breathing Rate and TIL for different Clevels under Chin Sealed ............ 30

Figure 10: Comparing Breathing Rate and TIL at different Clevels for Cheek and Chin Sealed

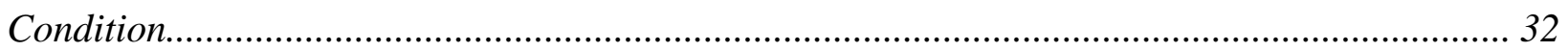




\subsection{INTRODUCTION}

\subsection{Background of Study}

Over a million workplaces with about five million workers in the US are subject to respirator compliance standards ( $\mathrm{Wu}, 2018$ ). Particulate matter with diameters below 2.5microns aerodynamic particle size has been shown to cause cancer and other health challenges for highrisk patients, especially pregnant women (Pashin \& Bakhitova, 1979; Geiger \& Cooper, 2010; Valero, 2014; Kim, Cho, \& Park, 2016). Workplace carcinogens are responsible for about 3-6 percent of patients diagnosed with cancer (FDA, 2020). Study has found that ultrafine particles have adverse health effects such as respiratory problems, and impairment of cardiovascular function (He et al., 2013). Respirators are essential whenever no feasible engineering control system exists to mitigate workers' exposure to airborne contaminants. Respiratory protection programs aim to prevent occupational illness by preventing or reducing workers' exposure to contaminated air.

Based on the U.S. Occupational Safety and Health Administration (OSHA) standard, 1910.134, employers must set up and implement a respiratory protection program for all workers that needs to wear a respirator (OSHA, 2020b). The OSHA standard says that appropriate respirators must be made available to employees by employers whenever such equipment is required to safeguard the employees' health, OSHA 1910.134(a)(2) (OSHA, 2020a). According to OSHA (OSHA, 2020c), employers must undertake the following procedures before selecting a respirator for workers.

- An exposure assessment in order to know the type and amount of hazardous exposure workers are exposed to. 
- Account for factors that can impact the selection of respirators.

- Understand the Assigned Protection Factors (APF) used to select respirators; and

- Be familiar with the different kinds of respirators and their important features.

An initial training must be provided for such employees and an annual training thereafter. The respirators must be worn by employees whenever they are working in a dangerous environment or when airborne contaminants are above exposure limits. An effective respirator provides protection against the airborne contaminant(s) with adherence to OSHA's APF.

Respirators can be made from various materials. Their filter efficiency degradation can be classified as N, P, or R (OSHA, 2020c). N implies the respirator is not resistant to oil. P implies the respirators is oil-proof and can be used for extended work shifts. $\mathrm{R}$ implies the respirator is oil - resistant and is only suitable for a one work shift (Gallant, 2006). Respirator filter efficiencies are established at three levels: 95\%, 99\% and 99.7\% (CDC, 1996). The percentage indicates how efficient the filter is against a most penetrating aerodynamic mass median particle (AMMD) size, $0.03 \mu \mathrm{m}$.

Every respirator type has its pros and cons. The level of protection given by the various respirator types is different. APFs refers to the level of protection that can be assigned to different classes of respirator (OSHA, 2020c). OSHA assigns APF to different classes of respirators to indicate the extent of protection they offer from airborne exposures. The extent of protection each respirator class offers increases as the APF number becomes higher.

A respirator can be either a positive pressure respirator (PPR) or a negative pressure respirator (NPR). PPR are respiratory protection devices that keep a positive pressure in the facepiece while it is being used in the proper manner. Pressure-demand and continuous flow respirators are two 
common types of PPRs. Pressure-demand respirators use a pressure regulator and exhalation valve to sustain the positive pressure in the respirator. In the occurrence of a leak, the regulator helps prevent penetration by sending a continuous flow of clean air thus preventing the wearer from breathing in contaminated air. PPRs are recommended for environments with hazardous waste. OSHA defines an NPR as "any tight-fitting respirator in which the air pressure inside the facepiece is negative during inhalation with respect to the ambient air pressure outside the respirator." NPRs draw air into the facepiece using the negative pressure created when the wearer inhales, thus if a leak occurs in the NPR or the NPR is improperly fitted, contaminated air is drawn into the facepiece by the wearer during inhalation. Examples of NPRs are some atmosphere-supplying respirators, mechanical filter respirators.

In this study, N95 respirators have been selected for use. According to FDA, "An N95 respirator is a particulate air-purifying respirator designed to achieve a very close facial fit and provide efficient filtration of airborne particles" (FDA, 2020). The respirator is named N95 because under testing conditions, "it is not resistant to oil and prevents at least 95 percent of particles $(0.3$ micron AMMD or larger) from going through the respirator" (CDC, 1996). However, an N95 respirator, like every other negative pressure respirator, will not provide full protection if a proper fit is not achieved. N95 respirators should not be used in oily atmospheres, to remove gases or vapors, or by people who have not passed a fit test with the respirator. A fit test is required for any worker using a negative pressure to ensure that a good fit is provided by the respirator.

The protection provided by all negative pressure particulate filtering respirator depends on its filtration efficiency and face seal leakage. For respirators equipped with exhalation valves, exhalation valve leakage may also occur. Proper respirator selection must consider the workplace conditions in which they will be used. OSHA requires that respirators must be certified by the 
National Institute for Occupational Safety and Health (NIOSH) and meet the certification requirements of NIOSH and the National Association for Fire Protection (NFPA) (He et al., 2013). $\mathrm{NIOSH}$ - certified respirators include negative pressure respirators classified as half-face respirators which can be further classified as filtering face-piece respirators (FFR) or elastomeric half-face respirators, full-face respirators, powered air-purifying respirators (PAPR) and gas masks; and supplied air respirators (SAR) classified as air-line respirators, and self-contained breathing apparatus (SCBA) operated as open circuit (positive pressure), and closed circuit devices (OSHA, 2019). Nuisance dust masks do not offer enough protection to be approved by NIOSH and therefore OSHA does not allow their use in industry where workers are exposed to known occupational airborne hazards. The two main categories of respirators are air-purifying respirators (APRs) and atmosphere-supplying respirators or supplied-air respirators (SARs) (OSHA, 2020a).

APRs remove contaminants from the air being breathed. They can be configured with a tightfitting facepiece or a loose-fitting helmet. Their air-purifying elements can be filters, gas and vapor cartridges or a combination of both. Particulate air-purifying respirators capture particles in the air and do not provide protection from gases or vapors. Gas and vapor air-purifying respirators protect against hazardous gases and vapor in the air. However, they do not provide protection from airborne particles. Combination air-purifying respirators provide protection against both particulates and gases and vapors (CDC, 1996).

SARs provide wearers air from a clean, uncontaminated source. They can be an air-supplied/airline respirator, SCBA or a combination of both (Gallant, 2006); OSHA, 2020c). Airline SARs use a hose, which can be certified for different lengths, to deliver clean air to the wearer from an uncontaminated source (Guzik, 2013). They can be used for long durations but, because of limited certified hose lengths, may limit the users' range of movement and may become damaged. On the 
other hand, SCBAs are "wearable clean air supply packs" (Gallant, 2006). They do not limit users' mobility but only provide protection for a limited amount of time. Supplied Air Respirators can either be tight-fitting or loose-fitting. Tight-fitting respirators require fit testing to ensure a tight seal between the respirator and individual's face and/or neck. The two types of SCBA are open circuit SCBA and closed circuit SCBA. Open circuit SCBAs release exhaled air into the surrounding while closed circuit SCBAs recycle and purify the exhaled air, removing the carbon dioxide and replenishing consumed oxygen from an oxygen cylinder.

\subsection{Fit Test}

A respirator offers reduced protection if it allows excessive face seal leakage due to an improper fit. Despite the importance of fit testing, employers must ensure employees are medically able to wear a respirator, based on a medical assessment, before conducting a fit test or wearing a respirator. A fit test assesses the seal between the respirator facepiece and the face of the wearer when it is worn (OSHA, 2020a). The actual fit test usually takes about 5 minutes; however, the whole respirator selection process takes about 15 to 20 minutes. OSHA requires that an approved fit test be performed and passed before an employee can start using a respirator and at least once a year thereafter. Fit tests should be performed with all the other head protective equipment the wearer is using such as hard hat, safety glasses and earmuffs, to ensure they do not affect the respirator's fit. Qualitative fit tests (QFT) and Quantitative fit tests (QNFT) are the 2 different classes of fit tests approved by OSHA (OSHA, 2019).

Qualitative fit testing (QFT) is usually utilized for testing half-face respirators. Half-face respirators cover the nose and mouth. With QFT, the outcome of the test, either pass or fail depends on the response of the individual to leakages determined from sense of taste or smell or reaction 
to irritants. OSHA accepts four QFT protocols: Isoamyl actetate, Saccharin, Bitrex and Irritant smoke (OSHA, 2019).

Quantitative fit testing (QNFT) can be utilized for testing any tight-fitting respirator. It uses a machine to perform an actual measurement on the quantity of leakage into the respirator. This testing requires a probe to be attached to the respirator's facepiece. A hose is usually used to connect the probe to the machine. The three types of QNFT protocols accepted by OSHA are generated aerosol, ambient aerosol and controlled negative pressure (OSHA, 2019)

After successfully passing a fit test, the worker must continue to use that same brand and model respirator. If a worker undergoes any change that could affect the fit of the respirator or finds the fit of the respirator to no longer be acceptable, the worker must select another respirator and be fit tested again to ensure an adequate fit.

\subsection{Total Inward Leakage (TIL)}

Rengasamy \& Eimer, 2012 defined TIL as the combination of particle penetration through the filter media, particle leakage through the face seal and any other source of leakage into the device. TIL is the amount of contaminated air (total particle penetration) that leaks into the respirator. The leakage could be from a variety of sources. The most common are face seal leakage, filter penetration, which can be affected by breathing volumes and loading, exhalation valves, and gaskets.

\subsection{Research Problem}

Oestenstad et al., 1990 developed methods for identifying location and shape of respirator face seal leak sites by deposition of a fluorescent tracer using half-face respirators worn on a 
mannequin. Oestenstad et al., 1990a also worked on the distribution of face seal leak sites on halfface respirator and their association with facial dimensions.

He et al., 2013 measured the effect of particle size on the penetration efficiency of elastomeric half-mask FFRs commonly used by first responders and firefighters. Gao et al., 2015 attempted to examine if the data obtained by using $\mathrm{NaCl}$ as the challenging aerosol to determine the efficiency of N95 FFRs is accurate in predicting the filter efficiency against combustion particles. They compared the penetration efficiency of other aerosol particles obtained from combustion of materials, such as burning wood, plastic and paper. Vo et al., 2015 studied the performance of different types of respirators against particles in the range of $10-400 \mathrm{~nm}$ using human subjects exposed to $\mathrm{NaCl}$ aerosols under simulated workplace activities. They stated that all respirators used in the study offered expected performance against all particle size ranges tested.

There is dearth of information on the effects of varying particle concentration on the penetration efficiency of FFRs, hence, this study aims to study the effect of varying $\mathrm{NaCl}$ particle concentration, sealing condition and breathing rate on the TIL as a result of the filtering efficiency of the filters. 


\subsection{LITERATURE REVIEW}

Different researches have been carried out on N95 filtering facepiece respirators. Oestenstad et al., 1990 developed methods for identifying the location and shape of respirator faceseal leak sites by deposition of a fluorescent tracer. They designed tested a system for exposing, conditioning, and generating aerosols in other to provide a test environment with stable aerosol concentration and size distribution of 4-methyl-7-diethylaminocoumarin. They detected faceseal leak locations on a respirator placed on a mannequin and worn by human subjects based on the build-up of the tracer aerosol and subsequent examination under long-wave ultraviolet illumination. Based on the study, they were able to identify test parameters for the ideal definition of leaks. Finally, they developed a photographic technique to document the identified leak sites.

Oestenstad et al., 1990b also worked on the distribution of faceseal leak sites on half-mask respirator and their association with facial dimensions. They isolated faceseal leaks on one brand of half-mask respirator worn by 73 human subjects by deposition of a fluorescent tracer aerosol during a standard quantitative fit test. They classified the identified leaks based on their shape and location, almost $90 \%$ of all observed leaks occurred at the nose or chin or were multiple leaks which included these sites. They found out that less than $75 \%$ of all leaks approximated the shape of a slit rather than a round orifice, and the prevalence of these leaks was affected by gender. Based on the study, a significant correlation of facial dimensions and fit factors were found for only three facial dimensions; none of which was used to define the test panel.

Results of the study suggest that respirator leakage is highly influenced by nose and chin leaks, that gender is a factor in how a respirator fit and that nasal dimension should be considered when describing a respirator test panel and choosing a respirator for an individual wearer. 
A study by Myers et al., 1986 illustrates the theoretical basis upon which a test method for evaluating the sampling error associated with in-facepiece sampling of half-mask respirators was developed. An experimental design to study the sampling bias in relation with in-facepiece sampling when different parameters for man/ respirator system was selected. The result of the study showed that when the current in-facepiece sampling technique is employed, significant errors can be made in estimating concentration within a respirator. They determined the sampling bias by collecting in-facepiece samples during the inhalation phase of the respiratory cycles. Based on the result, they concluded that quantitative fit data on half-mask respirators may be biased by a large measurement error.

Myers et al., 1988 studied the causes of in-facepiece sampling bias in half-facepiece respirators using acetone as the test agent and a manikin test system. The study attempted to provide reasons why the widely used technique of in-facepiece sampling does not provide representative sampling in half-facepiece respirators. They posited that the enormity of sampling bias varied and seems to be a function of many parameters of sampling, facepiece, and person; such as the location and depth of the sampling probe, the position of the face seal leak(nose vs chin, etc.), and interaction of the breathing patterns with the position of the face-seal leak, and the particular design of the half-faceseal. Based on this study it was evident that unrepresentative sample selection during inhalation is apparently due to uneven mixing of in-board faceseal leakage in the cavity of a half faceseal respirator. Also, they stated that within the experimental design limits, leak geometry, multiple leaks, and volumetrically different leak rates do not cause significant problems when conducting in-facepiece sampling on half-facepieces.

Myer \& Allender, 1988 studied the causes of in-facepiece sampling bias in full facepiece respirators. They stated that the sampling bias is due to several breathing patterns which is 
consistent with those observed on half - facepieces. The study showed that the in-facepiece sampling procedure is greatly influenced by airflow patterns such that a fair distinction of fullface components of different airflow patterns is difficult. The result of the study clearly shows that the airflow pattern created by the full-facepiece design had a rather pronounced impact on sampling. The study also posited that the in-facepiece sampling procedure studied does not seem to be adequate and suitable for providing reliable quantitative performance data on full facepieces. Finally, they stated that conclusions from previous studies which focused on sampling findings obtained from this or a significantly identical sampling method should be treated with great caution in the light of this new knowledge.

Bałazy et al., 2006 evaluated the filters against nanoparticles using manikin-based performance evaluation technique. This was done by assessing the efficiency of two N95 half-FFRs against nano-sized particles at two inhalation flow rates, 30 and 85 LPM. Particles in the particle diameter range of $\sim 30-70 \mathrm{~nm}$ showed maximum penetration values which indicated worst respiratory protection condition. They inferred, based on the theoretical simulation, that the highest penetration generally occurs at a particle diameter of $300 \mathrm{~nm}$ for respirators using mechanical filters; however, for pre-charged fiber filters, which are widely used for N95 respirators, the value shifts towards nano-sizes. Generally, their result suggests that laboratorybased evaluations have a good potential to adequately represent the respirator field performance.

Rengasamy \& Eimer, 2011 also studied the TIL of nanoparticles through FFRs. They measured filter penetration and TIL in a closed chamber on a breathing manikin by creating artificial leaks. Testing was done on four different respirator models. The study shows that the most penetrating particle size was $\sim 50 \mathrm{~nm}$, and filter penetrations were slightly higher for particles of 50 and 100 $\mathrm{nm}$ scale than for particles of 8 and $400 \mathrm{~nm}$ size. With higher flow rates, filter penetrations 
improved. The TIL values for all sizes of particles improved with the leak increased sizes of artificially introduced leaks. Also, the study indicated that for comparatively smaller size leakage, the TIL estimated for particles of $50 \mathrm{~nm}$ scale was $\sim 2$-fold higher than the values for particles of 8 and $400 \mathrm{~nm}$ scale suggesting that the TIL was higher for the more penetrating particles than for particles of smaller and greater distance. Their data suggest that there could be a higher concentration of nanoparticles in the breathing zone in workplaces where nanoparticles are present in the most penetrating particle size (MPPS) range, when leakage is minimal compared to filter penetration. The TIL / penetration ratios obtained for particles of $400 \mathrm{~nm}$ size were larger than the ratios obtained for particles of $50 \mathrm{~nm}$ size at the three different flow rates and leak sizes which imply that face seal leakage, not filter penetration, contributed to the TIL for larger particles. In the continuation of this study, Rengasamy \& Eimer, 2012 extended the to test filter penetration at sealed condition and TIL with artificially created leaks for 20-800 nm particle leaks at 8-40 1 minute volumes for four N95 models of filtering facepiece respirators using a breathing manikin to enhance the understanding of the significance of particle penetration through filter media and face seal leakage. They defined TIL as the combination of particle penetration through filter media and particle leakage via face seal and any device interfaces is known. Their result indicated higher filter penetration and TIL for $50 \mathrm{~nm}$ size particles, i.e. the most penetrating particle size than for 8 and $400 \mathrm{~nm}$ size particles.

Filter penetration for $45 \mathrm{~nm}$ size particles was significantly higher than the values for $400 \mathrm{~nm}$ size particles. Artificial leakage of test aerosols through increased size holes near the FFR sealing region showed higher TIL values for $45 \mathrm{~nm}$ particle size at different minute volumes, suggesting that the induced leakage allows test aerosols within the FFR, irrespective of particle size, while filter penetration influences the TIL for various particle size. 
Reponen et al, 2013 studied the effect of particle size on the performance of an N95 FFR and a surgical mask (SM) at various breathing conditions using manikin-based headform system and charge-equilibrated $\mathrm{NaCl}$ aerosol as the challenge aerosol. They sealed the FFR and surgical mask to a manikin head-form ensuring a perfect seal. Their filter penetration was determined by measuring the ratio of aerosol concentrations inside and outside the FFR/SM. They used four different cyclic breathing mean inspiratory flow rates and five different breathing frequency rates in their testing. Their results showed that the SM offered little protection against the tested aerosol sizes. Both the FFR and the SM filter penetration were significantly affected by particle size and breathing flow rate at penetration of less than 0.05 . They also found that at $\leq 50 \mathrm{~nm}$, TIL increases with increasing particle size for both FFR and SM but beyond $50 \mathrm{~nm}$, total penetration was not affected by particle size and breathing frequency.

Grinshpun, et al., 2013 measured the effects of particle size on the performance of elastomeric half-mask respirators. They utilized a single type elastomeric half-mask respirator donned on a breathing manikin equipped with two P-100 filters challenged with combustion aerosols from plastic, wood and paper. They found out that the performance of the respirator was significantly influenced by all the three factors (breathing flow rate, particle size, and combustion material) considered. For both respirator conditions (sealed and unsealed), plastic aerosol penetration through faceseal leakage maximum particle size was attained at above $100 \mathrm{~nm}$ but wood and paper aerosols did not show any strong peak. Their study indicates that the primary source of leakage is the nose region.

Yermakov, et al., 2013 studied the performance evaluation of elastomeric respirators against combustion particles using a manikin-based system. The study considered the effects of faceseal leakage, breathing flow rate, and combustion material on the overall (non-size- selective) 
penetration of combustion particles into P-100 half and full facepiece elastomeric respirators used by firefighter. They tested the respirators on a breathing manikin exposed to aerosols produced by combustion of wood, paper and plastic. Four different sealing conditions namely unsealed, nose-only sealed, nose and chin sealed and fully sealed were tested to evaluate the respirator leakage, also, the tests were performed using a single constant flow and three cyclic flows (30, 85, and 135 LPM). The result of the study showed that NIOSH certification criteria was met by the performance of P-100 respirator filters as it had a penetration of utmost $0.03 \%$. The study also showed that particle penetration through both unsealed and partially sealed half mask respirators are greatly influenced by the type of challenge aerosol used, and total particle penetration increases with increasing size of leakage.

He et al., 2014 studied how factors such as breathing frequency and flow rate affected the TIL of an elastomeric half-mask respirator. His testing was done by placing an elastomeric half-mask respirator on an advanced headform which had human facial characteristics. The manikin was challenged with wood, paper and plastic combustion aerosols. The study focused on generated aerosol particles in the 20 to $200 \mathrm{~nm}$ size range. Temperature and humidity were kept between $17^{\circ} \mathrm{C}$ to $22^{\circ} \mathrm{C}$ and $30 \%$ to $50 \%$ respectively. Three cyclic breathing flows (with Mean Inspiratory Flow, MIF, $=30,55$ and $85 \mathrm{~L} / \mathrm{min})$ and five breathing frequencies $(10,15,20,25$ and 30 breaths/min). They deployed a completely randomized factorial design. They utilized four replicates for every sequence of the tested breathing flow rate and frequency. Aerosol concentrations were measured inside and outside the respirator in 10 channels between 20 and 200nm. To obtain the TIL, they multiplied the ratio of the concentration inside the respirator to concentration outside the respirator by $100 \%$. The overall TIL was also determined by combining all 10 channels. The study concluded that irrespective of the breathing frequency, 
breathing flow and combustion material had significant effects on the TIL. Breathing frequency differed for the various aerosol and MIF combinations. Their study suggested plastic aerosols constitute higher exposure to TIL than the wood and paper aerosols.

Rengasamy et al., 2014 measured the contribution of filter penetration and faceseal leakage to TIL of submicron-size bioaerosols. They measured TIL values for different particles of $\mathrm{NaCl}$ which represents submicron-size bioaerosols with scanning mobility particle sizer. At increasing leak sizes and breathing minute volumes, TIL values increases. Higher efficiency N95 and SM models shows comparatively lower TIL. At different flow rates and leak sizes, TIL is affected by the filter efficiency of FFRs and SMs

Bergman et al., 2015 studied the correlation of N95 FFR fit measured on Human Subjects and a Static Advanced Headform (StAH).

The study was carried out by performing quantitative evaluations on test subjects in the laboratory, and the same respirator samples was used for both human subject and the StAH. The study showed that there is a positive correlation of respirator fit between the headform and test subjects. There is a clear linear association between overall fit factor $(\mathrm{FF})$ and manikin fit factor (MFF). The geometric mean (GM) values for FF were significantly higher than those for MFF for all respirators. For half of the respirators, GM FF and GM MFF levels varied greatly for humans and the StAH.

A weaker association was observed using only data paired by combination of subject / respirator combination where both the test subject and StAH had passed a real-time leak check before conducting the fit assessment. GM FF and GM MFF values were significantly different for $40 \%$ 
of the subject when data by test subject was used. Generally, according to the study, the advanced headform system has potential for assessing fit for some N95 FFR model/sizes.

\subsection{Research Gap}

This study will help to understand

i. The effect of varying concentration on the TIL

ii. The effect of sealing conditions on the TIL at different breathing rates

iii. If TIL response vary significantly with varying sealing conditions, given varying breathing rate and varying concentration levels.

\subsection{Objectives}

Although several studies have been carried out regarding this subject, however, none of the studies reviewed considered effects of sealing conditions, breathing frequency and particle concentration on TIL with $\mathrm{NaCl}$ as the challenge aerosol particle. Hence, this study aims to determine the effects of sealing conditions, breathing frequency and particle concentrations on the total inward leakage of N95 FFRs using $\mathrm{NaCl}$ as the particle source. The experiments were performed using different aerosol particle $(\mathrm{NaCl})$ concentration levels and sealing conditions under different breathing rates. The breathing flow rates used were 15 LPM, 30 LPM, 55 LPM and 85LPM. For each concentration, one of three concentration levels $100000 / \mathrm{cm}^{3}(100 \mathrm{~K}), 200000 / \mathrm{cm}^{3}(200 \mathrm{~K})$ and $400000 / \mathrm{cm}^{3}(400 \mathrm{~K})$, with an error allowance of 30 percent was used. 


\subsection{Research Hypothesis}

Ho: Particle concentration, sealing condition and breathing rate have no significant effect on TIL of N95 FFRs at 95\% confidence level.

Ha: Particle concentration, sealing condition and breathing rate have significant effect on TIL of N95 FFRs at 95\% confidence level.

Hypothesis of the study was represented in the mathematical model below:

$\mathrm{TILSC}_{S \mathrm{C}}=\beta \mathrm{o}+\beta_{1} \mathrm{~B}+\beta_{2} \mathrm{C}+\beta_{3} \mathrm{BC}+£$

$\mathrm{H}_{\mathrm{O}}=\beta_{3}=0$ where $\mathrm{B}$ is the breathing rate at the $4 \mathrm{MIF}, 15,30,55$, and 85 ; $\mathrm{C}$ is concentration and $\mathrm{BC}$ is the interaction between Breathing flow rate and the concentration. TILsc is the total inward leakage at the different sealing conditions. 


\subsection{METHODOLOGY}

\subsection{Materials}

Materials used for the experiment includes Moldex 2200N95 Series, a test chamber, a manikin (Model: Full round molded male manikin display head), needles used for introducing artificial leaks, a TSI Nanoscan SMPS 3910, and a model 8026 particle generator.

These materials are similar to those utilized by He et al., 2018.

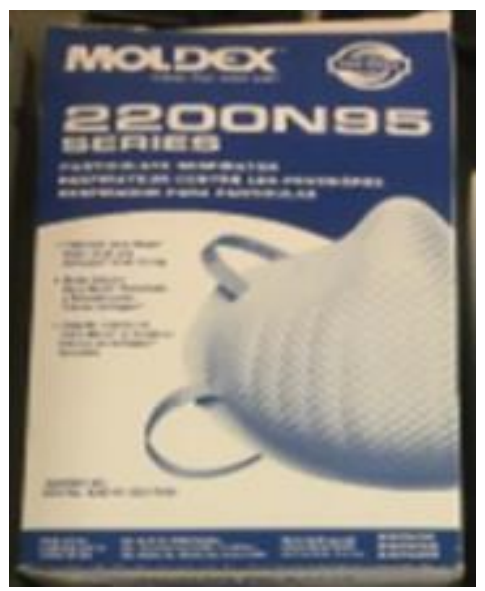

Figure 1: Moldex 2200N95 Series (Non Exhalative Valve)

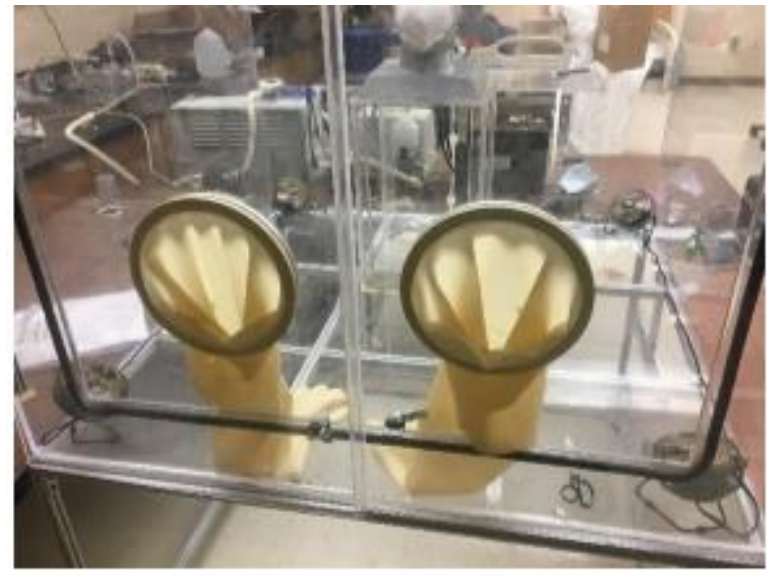

Figure 2: Test Chamber 


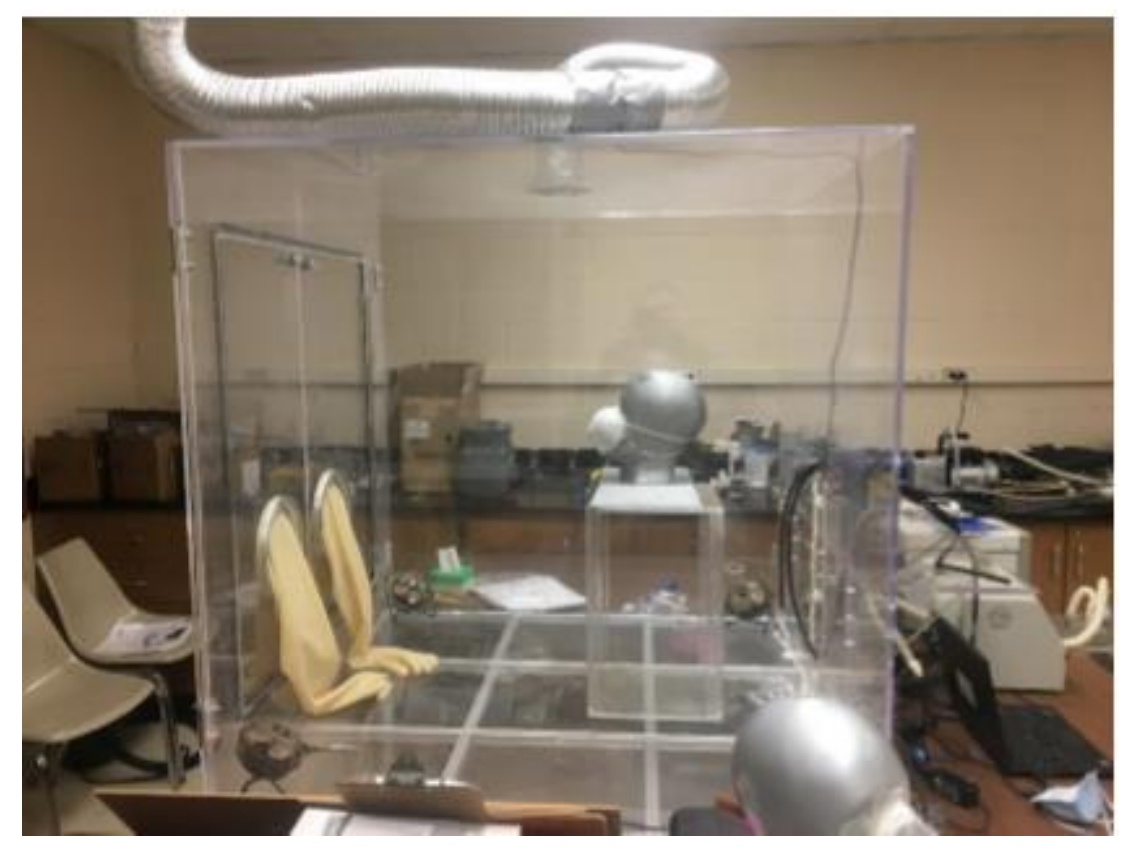

Figure 3: Experimental Setup with donned Manikin

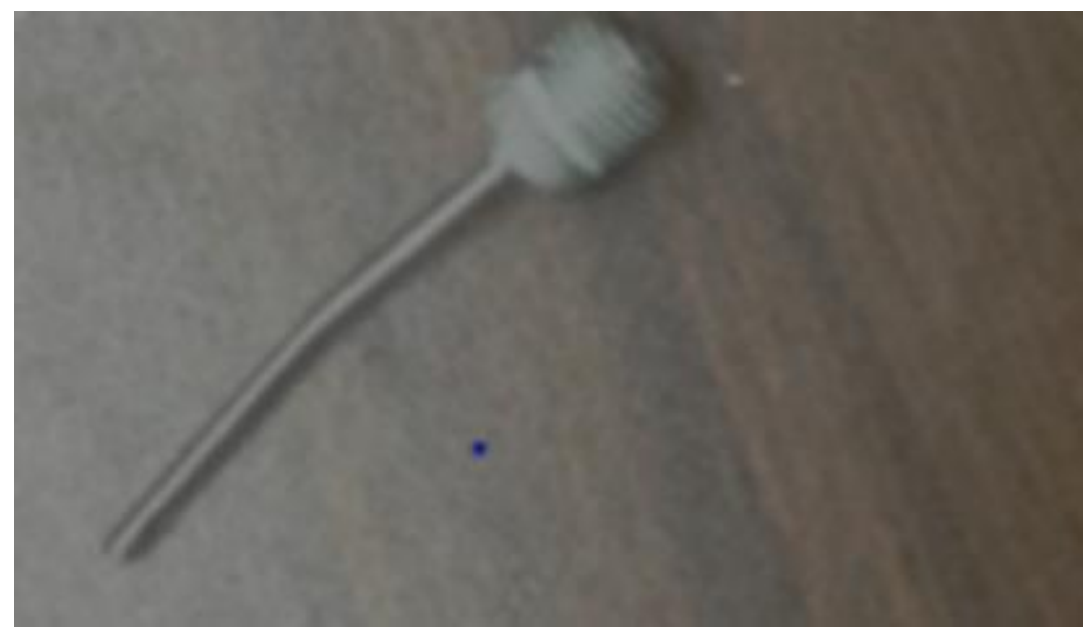

Figure 4: Needle used to induce Artificial Leak 


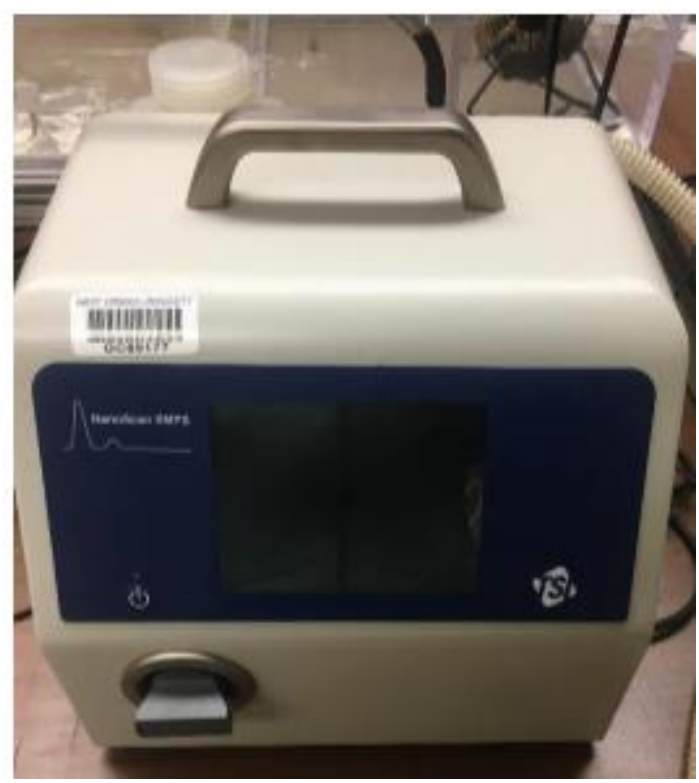

Figure 5: TSI Nanoscan SMPS 3910

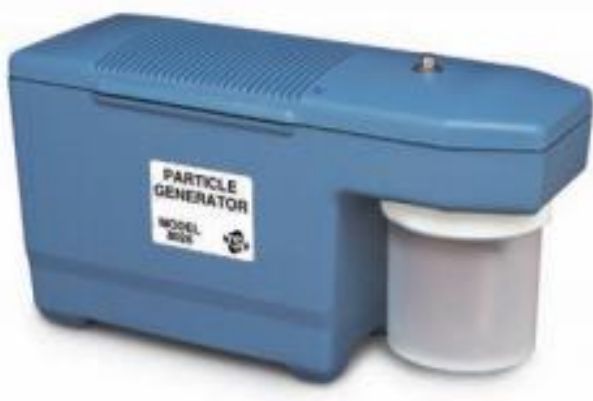

Figure 6: Model 8026 Particle Generator 


\subsection{Experimental Setup}

The experimental procedure followed was used by He et al., 2013. The experiment was carried out in the indoor testing laboratory of the Mineral Resource building (MRB) Room 242, Statler College of Engineering and Mineral resources West Virginia University. We carried out the sample collection at room temperature, with varying concentrations, sealing conditions and flow rates.

To generate the challenge agent used for the study, we followed the method used by He et al., 2014; We aerosolized a liquid salt solution using a particle generator (Model 8026, TSI Inc., Shoreview, Minn.), which was charge-equilibrated by passing through a $85 \mathrm{Kr}$ electrical charge equilibrator prior to being released inside the test chamber. We ensured that the particle generator operated for at least one hour to achieve a uniform $\mathrm{NaCl}$ concentration in the chamber; it continued operating during the testing to maintain a stable particle concentration level. The $\mathrm{NaCl}$ concentration inside the challenge chamber ranged from 30,000 to $1,000,000$ particles/cm3. The high ambient level was chosen to assure that enough particles would be detected inside the respirator.

The Moldex 2200 N95 Series FFR is not equipped with an exhalative valve. The FFR was placed on a manikin head-form made of hard plastic. The FFR was sealed to the manikin and placed in a test chamber which had dimensions of $46 \mathrm{~cm} \times 46 \mathrm{~cm} \times 46 \mathrm{~cm}$. The FFR was equipped with a needle for introducing artificial leaks at the nose, chin and cheek areas. These areas have been identified from previous studies as the region where most faceseal leakages occur (Crutchfield \& Park, 1997; He et al., 2013). 
We established four sealing conditions, namely fully sealed, chin and cheek sealed (nose opened), chin sealed (nose and cheek opened) and fully opened, in other to investigate the effect of the faceseal leakage on the performance of the respirator. We applied silicon sealant to the face of the manikin to ensure no other source of leakage exists other than what we desire. According to He et al., 2013, the fully sealed condition essentially targeted the efficiency of the N95 filters installed on the half-mask respirator, assuming no penetration through the exhalation valve. The unsealed and partially sealed conditions permitted evaluation for both penetration pathways: filter penetration and faceseal leakage.

For each combination of test conditions, the experiment was repeated seven times. A condensation particle counter (CPC, Model 3007; TSI Inc., Shoreview, Minn.) which has capability to detect particle sizes of at least $0.1 \mu \mathrm{m}$, was used to measure aerosol concentrations inside and outside the respirator.

Using the TSI Model 8025-N95 Suit Test Probe kit, the half-mask was probed between the manikin's nose and upper lip for sampling from inside the respirator. The Nano-ID can calculate an aerosol particle size distribution from 5 to $500 \mathrm{~nm}$, which is referred to as scan range, over a range of mobility diameters (an equivalent diameter of a spherical particle with the same mobility, (Kulkarni et al., 2011). The sampling probe was connected to the manikin's nose and upper lip through the back of the neck.

The particle penetration (through both pathways) was determined for each particle size (dp) as the ratio of inside and outside concentrations. 


\section{Experimental Design}

The experimental design that was used for sample collection and analysis is described using the table below. The experiment was carried out 6 times at 1 minute each. This indicates 3 replicates

Table 1: Experimental Design

\section{Sealing Condition Concentration Breathing Rate}

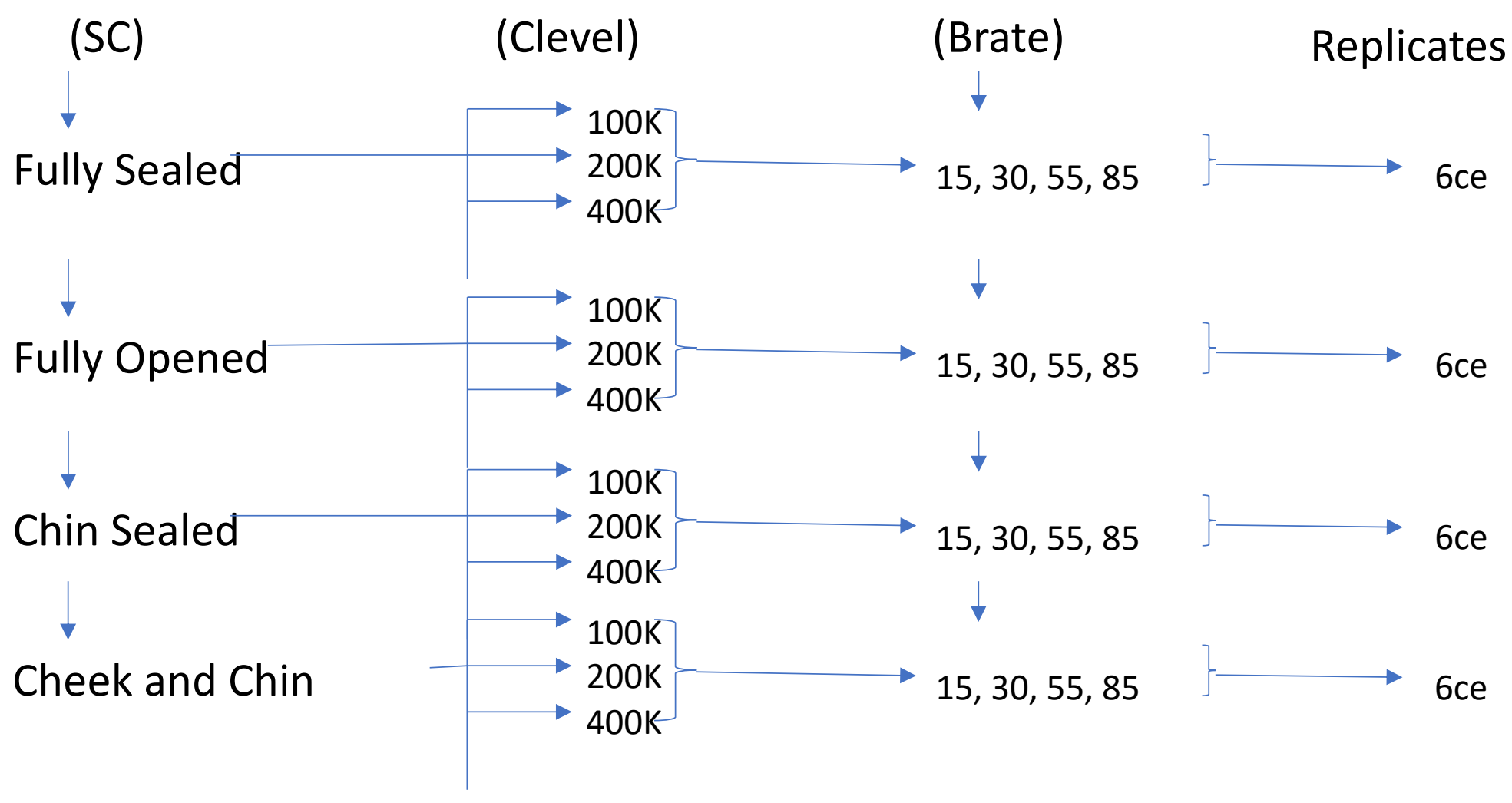




\subsection{Data Collection}

According to Myers et al.,1988, aerosols does not mix equally within the respirator cavity during the inhalation phase of the respiratory cycle, hence, we have chosen to use constant flow with MIF of $15,30,55$ and $85 \mathrm{~L} / \mathrm{min}$ for the experiment. We used a completely randomized factorial design for the breathing frequency and flow rate which was replicated seven time at one minute per replicate. Particle size-independent (overall) concentrations inside and outside the FFR were obtained on the laptop setup with the Nanoscan manager software, having a total sampling time of 1 min with a time resolution of $1 \mathrm{sec}$ per cycle. Mean particle size-specific concentrations inside $\left(C_{\text {in__ }} d_{p}\right)$ and outside $\left(C_{\text {out_}} d_{p}\right)$ of the FFR were measured using TSI Nanoscan 3910 SMPS. Each particle size-specific concentration $\left(\mathrm{C}_{\mathrm{in} \_} \mathrm{d}_{\mathrm{p}}\right.$ or $\left.\mathrm{C}_{\text {out_}} \mathrm{d}_{\mathrm{p}}\right)$ was sampled for 6 minutes.

Total Inward Leakage was obtained by finding the percentage of the ratio of total mean particle concentration inside the FFR and total mean particle concentration outside the FFR. 


\subsection{Data Analysis}

Visual presentation of result was done with Python 3.8 and data analysis was carried out using R version 3.6.0 (2019-04-26). The analysis of the relationship between TIL and the effect of breathing rate, particle concentration and sealing condition was performed using two-way Analysis of Variance (ANOVA). The statistical model statement is as follows:

$$
\begin{gathered}
\text { TILSC }_{S O} \beta+\beta_{1} B+\beta_{2} C+\beta_{3} B C+£ \\
H_{O}=\beta_{3}=0
\end{gathered}
$$

where $\mathrm{B}$ is the breathing rate at the $4 \mathrm{MIF}, 15,30,55$, and 85 ; $\mathrm{C}$ is concentration and $\mathrm{BC}$ is the interaction between Breathing flow rate and the concentration. TILsc is the total inward leakage at the different sealing conditions. 


\subsection{RESULT AND DISCUSSION}

The methodology was designed to demonstrate the response of TIL under different sealing conditions ( fully sealed, fully opened, cheek and chin sealed and chin sealed) for varying concentrations level (100k, 200k and 400k) for four levels of breathing rate: 15, 30, 55 and 85 LPM.

Our results are expected to answer the following:

1. What is the effect of varying concentration on the TIL?

2. What is the effect of sealing conditions on the TIL at different breathing rates?

3. Does the TIL response vary significantly with varying sealing conditions, given the varying breathing rate and varying concentration levels?

The result is as follows: 


\subsection{Fully Sealed}

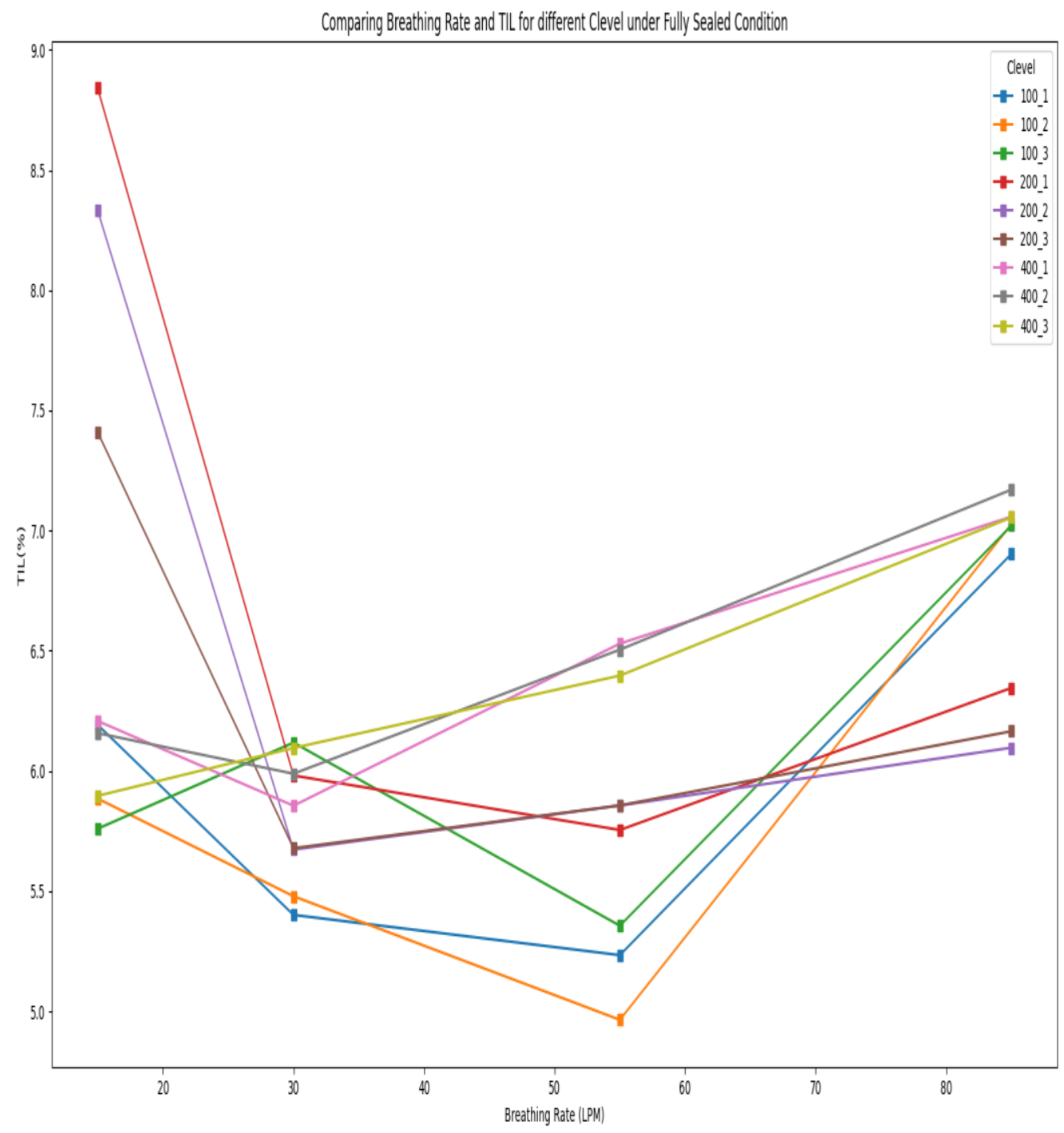

Figure 7:Comparing Breathing Rate and TIL for different Clevels under fully Sealed Condition 
Table 2: Analysis of Variance Table Without Interaction for Fully Sealed Condition

Response: TIL

Breathing Rate

Df Sum Square

Concentration Level

10.1988

Mean Square

$F$ value

$\operatorname{Pr}(>\mathrm{F})$

$1 \quad 0.8946$

0.19881

0.2968

0.5896

Residuals

$33 \quad 22.1070$

0.89465

1.3355

0.2561

Table 3: Analysis of Variance Table for Fully Sealed Condition with interaction

Response: TIL

$\begin{array}{lccccc} & \text { Df } & \text { Sum Square } & \text { Mean Square } & \text { F value } & \operatorname{Pr}(>F) \\ \text { Concentration Level } & 1 & 0.8946 & 0.89465 & 1.3195 & 0.2592 \\ \text { Breathing Rate } & 1 & 0.1988 & 0.19881 & 0.2932 & 0.5919 \\ \text { Clevel : Brate } & 1 & 0.4096 & 0.40957 & 0.6041 & 0.4427 \\ \text { Residuals } & 32 & 21.6974 & 0.67804 & & \end{array}$




\subsection{Fully Opened}

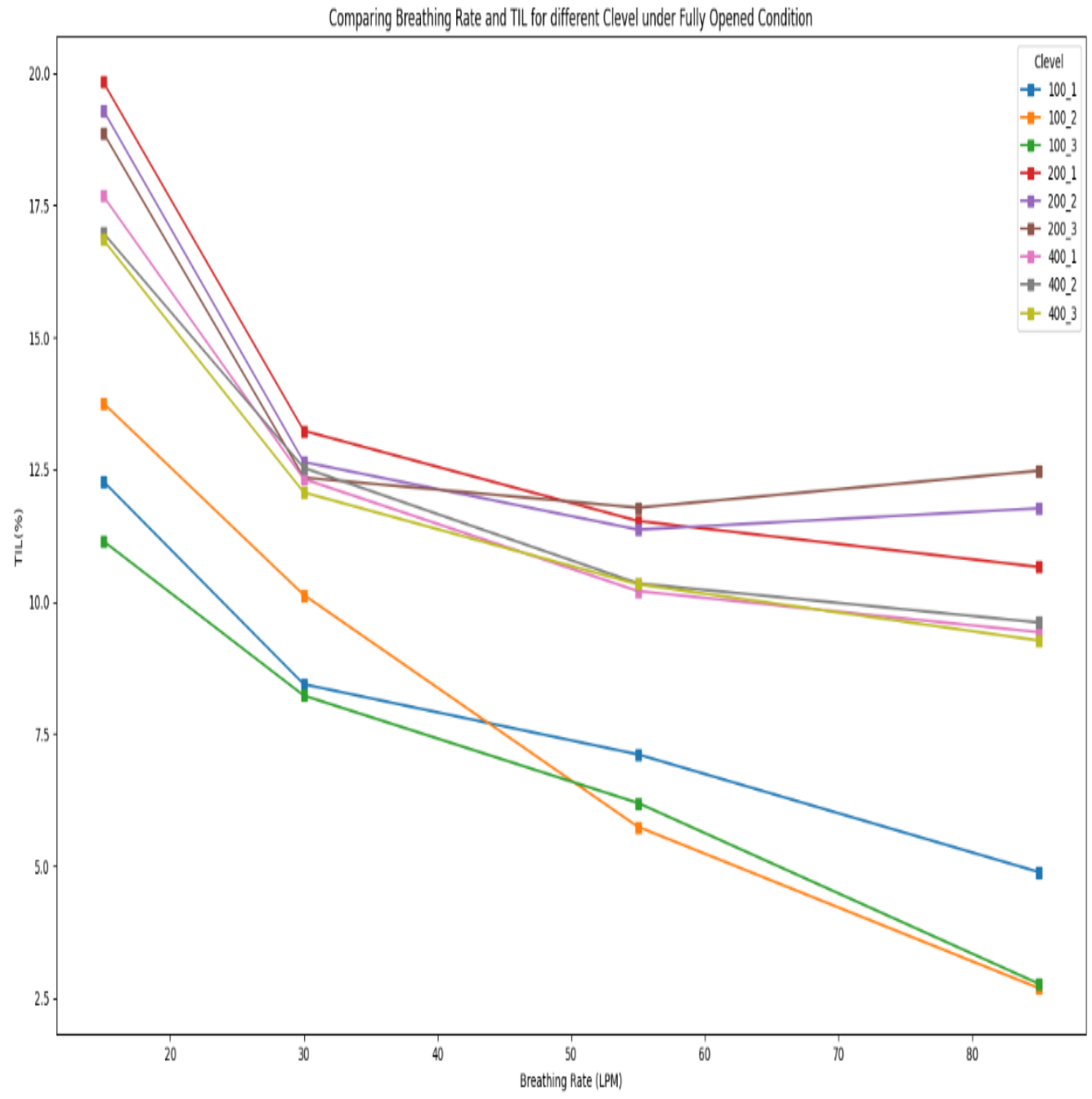

Figure 8: Comparing Breathing Rate and TIL at Different Clevels for Fully Opened Condition

Figure 8 shows the visual representation results of TIL at varying breathing rate and concentration level for fully opened sealing condition. At all the concentration levels considered, increases in the breathing rate resulted in lower percentage TIL. 
Table 4: Analysis of Variance for Fully Opened Condition without Interaction

Response: TIL

$\begin{array}{lccccc} & \text { Df } & \text { Sum Square } & \text { Mean Square } & \text { F value } & \operatorname{Pr}(>\mathrm{F}) \\ \text { Concentration Level } & 1 & 78.341 & 78.341 & 10.068 & 0.003257 * * \\ \text { Breathing Rate } & 1 & 276.922 & 276.922 & 35.587 & 1.068 \mathrm{e}-06 \text { * ** } \\ \text { Residuals } & 33 & 256.791 & 7.782 & & \end{array}$

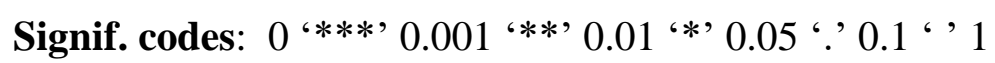

Table 5: Analysis of Variance for Fully Opened Condition with Interaction

Response: TIL

$\begin{array}{lccccc} & \text { Df } & \text { Sum Square } & \text { Mean Square } & \text { F value } & \operatorname{Pr}(>\mathrm{F}) \\ \text { Concentration Level } & 1 & 78.341 & 78.341 & 9.8127 & 0.003692 * * \\ \text { Breathing Rate } & 1 & 276.922 & 276.922 & 34.6863 & 1.495 \mathrm{e}-06 * * * \\ \text { Clevel : Brate } & 1 & 1.315 & 1.315 & 0.1648 & 0.687505 \\ \text { Residuals } & 32 & 255.475 & 7.984 & & \end{array}$

Signif. codes: 0 ‘***’ 0.001 '**’ 0.01 '*’ 0.05 '? 0.1 ' ' 1

Ho $=\beta 3=0$

Table 4 shows the analysis of variance for TIL response when interaction between breathing rate and concentration level is not considered while Table 5 shows analysis of variance for TIL response when there is interaction between breathing rate and concentration levels. 


\subsection{Chin Sealed}

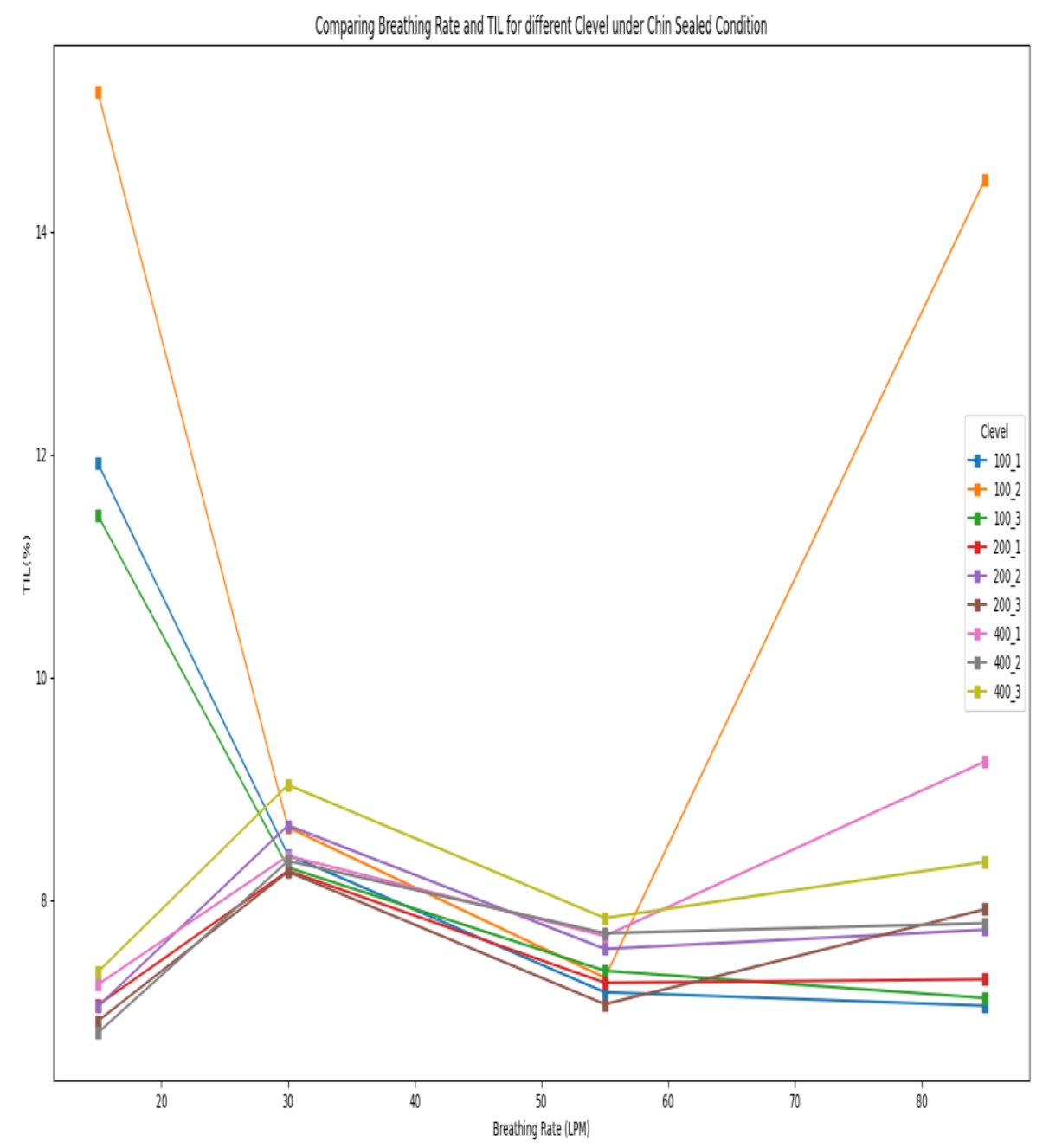

Figure 9: Comparing Breathing Rate and TIL for different Clevels under Chin Sealed

Figure 9 presents the data for TIL at varying breathing rate and particle concentration levels for Chin sealed (nose and cheek opened) sealing condition. In general, at higher concentration, there is higher percentage TIL value for any given breathing rate. 
Table 6: Analysis of Variance Table for Chin Sealed Condition without Interaction

Response: TIL

$\begin{array}{lclccc} & \text { Df } & \text { Sum Square } & \text { Mean Square } & \text { F value } & \operatorname{Pr}(>F) \\ \text { Concentration Level } & 1 & 9.712 & 9.7124 & 3.6516 & 0.1130 \\ \text { Breathing Rate } & 1 & 1.654 & 1.6536 & 0.4515 & 0.5063 \\ \text { Residuals } & 33 & 120.875 & 3.6629 & & \end{array}$

Table 7: Analysis of Variance Table for Chin Sealed Condition with Interaction

Response: TIL

$\begin{array}{lccccc} & \text { Df } & \text { Sum Square } & \text { Mean Square } & \text { F value } & \operatorname{Pr}(>F) \\ \text { Concentration Level } & 1 & 9.712 & 9.7124 & 2.7689 & 0.1059 \\ \text { Breathing Rate } & 1 & 1.654 & 1.6536 & 0.4714 & 0.4973 \\ \text { Clevel : Brate } & 1 & 8.628 & 8.6283 & 2.4598 & 0.1266 \\ \text { Residuals } & 32 & 112.247 & 3.5077 & & \end{array}$

Analysis of variance for TIL response for a model that does not consider the interaction between breathing rate and concentration level is presented in Table 6 while Table 7 presents analysis of variance for TIL response for a model that considers interaction between breathing rate and concentration levels. 


\subsection{Cheek and Chin Sealed}

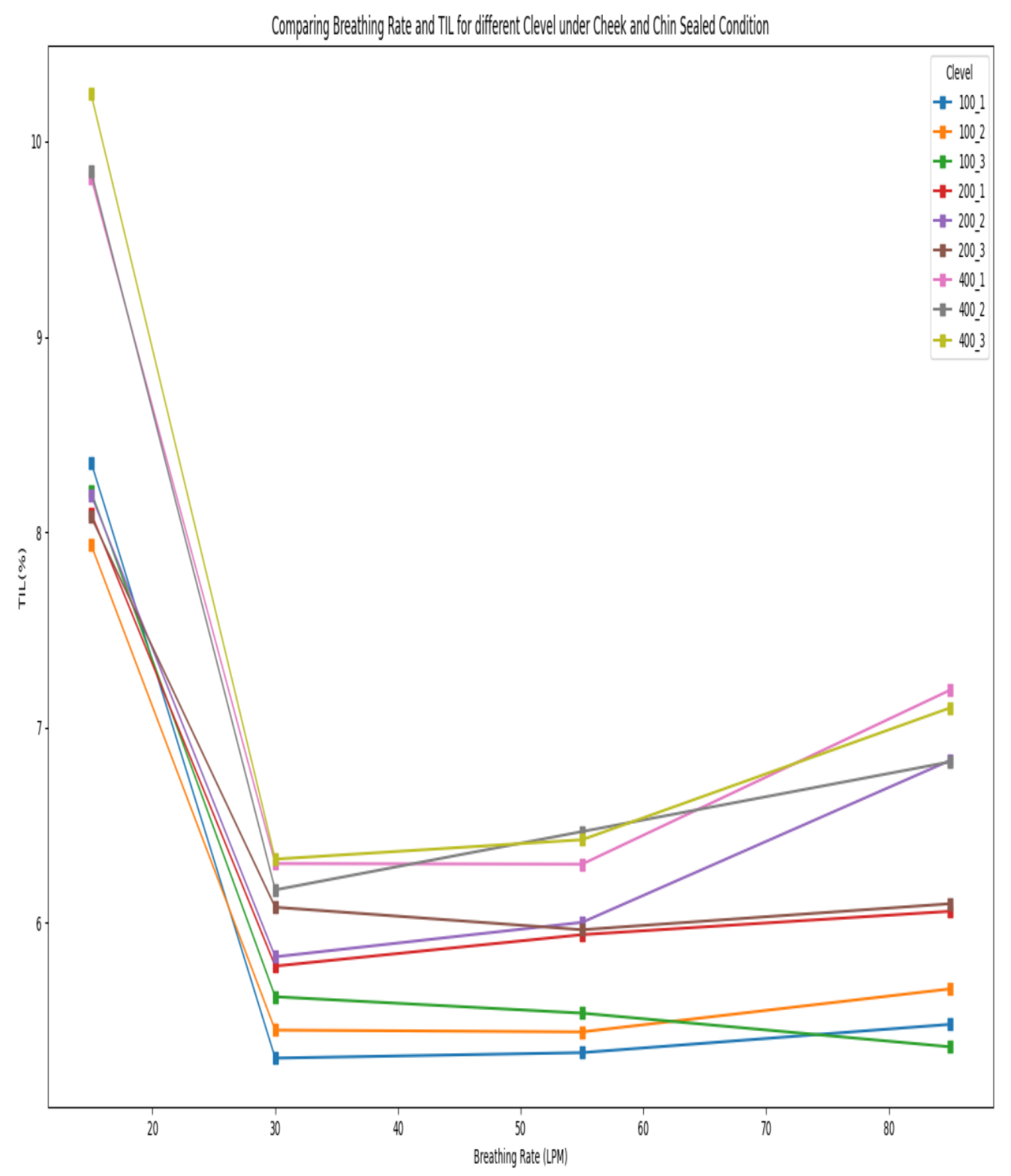

Figure 10: Comparing Breathing Rate and TIL at different Clevels for Cheek and Chin Sealed Condition

Figure 10 shows the visual representation of TIL at varying breathing rate and concentration level for cheek and chin sealed sealing condition. 
Table 8: Analysis of Variance for Cheek and Chin Sealed Condition without Interaction

Response: TIL

$\begin{array}{lclccl} & \text { Df } & \text { Sum Square } & \text { Mean Square } & \text { F value } & \operatorname{Pr}(>\mathrm{F}) \\ \text { Concentration Level } & 1 & 10.082 & 10.0824 & 8.9879 & 0.0051337 * * \\ \text { Breathing Rate } & 1 & 17.139 & 17.1394 & 15.2788 & 0.0004355 * * * \\ \text { Residuals } & 33 & 37.019 & 1.1218 & & \end{array}$

Signif. codes: 0 ‘***’ 0.001 ‘**’ 0.01 ‘*’ 0.05 ‘' 0.1 “ ' 1

Table 9: Analysis of Variance for Cheek and Chin Sealed Condition with Interaction

Response: TIL

$\begin{array}{lccccl} & \text { Df } & \text { Sum Square } & \text { Mean Square } & \mathrm{F} \text { value } & \operatorname{Pr}(>\mathrm{F}) \\ \text { Concentration Level } & 1 & 10.082 & 10.0824 & 8.7242 & 0.0058446 \text { ** } \\ \text { Breathing Rate } & 1 & 17.139 & 17.1394 & 14.8305 & 0.0005312 \text { *** } \\ \text { Clevel : Brate } & 1 & 0.037 & 0.0367 & 0.0317 & 0.8597150 \\ \text { Residuals } & 32 & 36.982 & 1.1557 & & \end{array}$

$---$

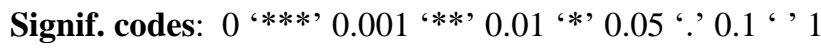

Table 8 presents the analysis of variance for TIL response when interaction between breathing rate and concentration level is not considered while Table 9 shows analysis of variance for TIL response when there is interaction between breathing rate and concentration levels.

The analysis shows that there is no statistically significant variance in the mean value of the TIL response when interaction between breathing rate and concentration level was considered. Similar result was obtained when TIL response was examined without considering interaction between breathing rate and concentration level. 


\subsection{DISCUSSION}

This section explains the results that are presented in chapter 4 of this report.

\subsection{Fully Sealed}

Figure 7 shows the visual representation results of TIL at varying breathing rate and concentration level for fully sealed sealing condition. Each line represents the TIL and breathing rate for each replicate at different sealing conditions. TIL response to breathing rate tend to vary in terms of trends followed by each of the replicates. This could be attributed to the sampling bias that might be introduced by our sampling method which does not position the sampling probe at the central line.

An analysis of variance was performed on the result to determine the statistical significance among the variables, the result is shown in Table 2, and 3 .

The mean value of the TIL response does not vary significantly with the changes in breathing rat e.

Ho $=\beta 3=0$

Table 2 shows the analysis of variance for TIL response when interaction between breathing rate and concentration level is not considered while Table 3 shows analysis of variance for TIL response when there is interaction between breathing rate and concentration levels.

For a fully sealed conditions, the variables have no effect on the TIL. Hence, TIL is determined by the quality of the filter material (model) or filter type (exhalative or non-exhalative). Invariably, this implies that for a worker who is working under fully sealed condition, that is, properly fitted mask, the concentration of the exposures and breathing rate do not affect the effectiveness of the mask. 


\subsection{Fully Opened}

We visually represented results of TIL response at varying breathing rate and concentration level for fully opened sealing condition in figure 8. Each line represents the TIL response and breathing rate for each of the replicates at different concentration levels. TIL response tends to reduce at higher concentration as breathing rate increases. This could be attributed to the needles going sonic as breathing rate increases. Sonic effect could be explained as follows: Particles entre either through the filters or the perforations in the needle. When particles enter through this needle, there is a limit beyond which no more particle enters through the perforations in the needle, at this point, only penetration through the filter media accounts for TIL. Hence, this is called sonic effect.

Table 4 shows the analysis of variance for TIL response when interaction between breathing rate and concentration level is not considered while Table 5 shows analysis of variance for TIL response when there is interaction between breathing rate and concentration levels.

Upon the analysis, both breathing rate and concentration levels affected TIL response for the two models that were considered. This shows that at 0.05 confidence level, both factors considered affected TIL response.

\subsection{Chin Sealed}

Figure 9 presents the data for TIL at varying breathing rate and particle concentration levels for Chin sealed (nose and cheek opened) condition. In general, at higher concentration, there is high er percentage TIL value for any given breathing rate. There are some inconsistencies in some of $t$ he replicates as shown by the figure, and this could be attributed to the sampling bias. Analysis of variance was carried out and the results are presented in Table 6 and 7. 
Table 6 presents the analysis of variance for TIL response for a model that does not consider the interaction between breathing rate and concentration level while analysis of variance for TIL response for a model that considers interaction between breathing rate and concentration levels

is presented in Table 7.

The result shows that there is no statistically significant variance in the percentage TIL response for chin sealed condition for all the models considered.

In practical applications, this sealing condition leaves the breathing zone open, hence, if a worker partially seals the chin area, exposure to particles is highly significant.

\subsection{Cheek and Chin Sealed}

Figure 10 shows the visual representation of TIL at varying breathing rate and concentration level for cheek and chin sealed condition.

As concentration increases, there is higher percentage TIL value with increasing breathing rate.

An analysis of variance was performed on the result to determine the statistical interactions among the variables, the result is shown in Table 8 and 9.

Table 8 presents the analysis of variance for TIL response when interaction between breathing rate and concentration level is not considered while Table 9 shows analysis of variance for TIL response when there is interaction between breathing rate and concentration levels.

The analysis shows that there is statistically significant variance in the mean value of the TIL response when interaction between breathing rate and concentration level was considered. Similar result was obtained when TIL response was examined without considering interaction 
between breathing rate and concentration level. This implies that at 0.05 confidence level, TIL response is significantly affected by breathing rate and concentration level. 


\subsection{Limitation of Study}

The following are the limitations to this study

i. Obtaining accurate particle concentration value was almost impossible and that was why we set a range of $\pm 30 \%$ for the concentration level of the aerosol particles or considering more numbers of repetitions.

ii. The position of the sampling probe (back of the neck) may affect the sampling bias level.

iii. Preparing the solution from granular or solid $\mathrm{NaCl}$ was an issue. Getting homogenous mixture was an issue.

iv. The experimental design was not perfect to obtain a result that would be able to generate the power statistics. This could have helped to determine how many more replicates would be needed to obtain significance for chin sealed and fully sealed condition, if significance exists. 


\subsection{CONCLUSIONS AND RECOMMENDATIONS}

Recall that the aim of this study is to assess the effect of varying $\mathrm{NaCl}$ particle concentration, sealing conditions and breathing rate on the TIL as a result of the filtering efficiency of the filters. Our results have shown that TIL rarely vary with change in the parameters.

\subsection{Conclusions}

The response for TIL differs with the change in sealing conditions, varying concentrations of $\mathrm{NaCl}$ particle and breathing rates only under fully opened condition.

The fully opened condition offers no significant protections to the worker and at high concentration levels, the breathing rate and concentration level significantly had effects on the percentage value of the TIL.

In general, for most sealing conditions, the higher the concentration, the higher the percentage $\mathrm{TIL}$ at a given breathing rate.

The data trend shows that the TIL varies directly with the breathing rate. There is an higher penetration at higher breathing rate for all concentration levels, more significantly at lower concentrations.

In conclusion, this study showed that in studying the effect of varying $\mathrm{NaCl}$ particle concentration, sealing conditions and breathing rate on the TIL, it is only under both fully opened and cheek and chin sealed conditions that the mean TIL response is significantly affected by the factors in consideration. Hence, workers should not expose their nose region at any time to prevent exposure. 


\subsection{Recommendations}

Further studies should be done to different models of respirators such as respirators with exhalative valve, and different manufacturers such as Gerson N95 FFR.

Similar studies could be performed using a sampling probe at the central line, as this may reduce sampling bias.

Studies should also be conducted with constant flow rather than cyclic flow. 


\subsection{REFERENCES}

Bałazy, A., Toivola, M., Reponen, T., Podgórski, A., Zimmer, A., \& Grinshpun, S. A. (2006). Manikin-based performance evaluation of N95 filtering-facepiece respirators challenged with nanoparticles. Annals of Occupational Hygiene, 50(3), 259-269. https://doi.org/10.1093/annhyg/mei058

Bergman, M. S., He, X., Joseph, M. E., Zhuang, Z., Heimbuch, B. K., Shaffer, R. E., ... Wander, J. D. (2015). Correlation of respirator fit measured on human subjects and a static advanced headform. Journal of Occupational and Environmental Hygiene, 12(3), 163-171. https://doi.org/10.1080/15459624.2014.957832

CDC. (1996). CDC - NIOSH Publications and Products - NIOSH Guide to the Selection and Use of Particulate Respirators Certified Under 42 CFR 84 (96-101). Retrieved September 1, 2020, from NIOSH website: https://www.cdc.gov/niosh/docs/96-101/default.html

Crutchfield, C. D., \& Park, D. L. (1997). Effect of leak location on measured respirator fit. American Industrial Hygiene Association Journal, 58(6), 413-418. https://doi.org/10.1080/15428119791012649

FDA. (2020). N95 Respirators, Surgical Masks, and Face Masks |FDA. Retrieved September 1, 2020, from US FDA website: https://www.fda.gov/medical-devices/personal-protectiveequipment-infection-control/n95-respirators-surgical-masks-and-face-masks

Gallant, B. J. (2006). Hazardous Waste Operations and Emergency Response Manual. In Wiley. https://doi.org/10.1002/0470007257

Gao, S., Kim, J., Yermakov, M., Elmashae, Y., He, X., Reponen, T., \& Grinshpun, S. A. (2015). Penetration of combustion aerosol particles through filters of NIOSH-certified filtering 
facepiece respirators (FFRs). Journal of Occupational and Environmental Hygiene, 12(10), 678-685. https://doi.org/10.1080/15459624.2015.1043057

Geiger, A., \& Cooper, J. (2010). Overview of Airborne Metal regulations, Exposure Limits, Health Effects and Contemporary Research. Cooper Environmental Services.

Guzik, A. (2013). Essentials for Occupational Health Nursing. In Essentials for Occupational Health Nursing. https://doi.org/10.1002/9781118783252

He, X., Grinshpun, S. A., Reponen, T., McKay, R., Bergman, M. S., \& Zhuang, Z. (2014). Effects of breathing frequency and flow rate on the total inward leakage of an elastomeric half-mask donned on an advanced manikin headform. Annals of Occupational Hygiene, 58(2), 182-194. https://doi.org/10.1093/annhyg/met053

He, X., Grinshpun, S. A., Reponen, T., Yermakov, M., McKay, R., Haruta, H., \& Kimura, K. (2013). Laboratory evaluation of the particle size effect on the performance of an elastomeric half-mask respirator against ultrafine combustion particles. Annals of Occupational Hygiene, 57(7), 884-897. https://doi.org/10.1093/annhyg/met014

He, X. K., Ph, D., Guffey, S. E., Ph, D., Bergman, M., Npptl, N., \& Virginia, W. (2018). A Labbased Study of N95 FFRs Against Cigarette Smoke Under Varying Concentrations and Sealing Conditions Jacob Davis Thesis submitted to the Statler College of Engineering and Mineral Resources at West Virginia University in partial fulfillment of the re.

He, X., Reponen, T., McKay, R. T., \& Grinshpun, S. A. (2013a). Effect of particle size on the performance of an N95 filtering facepiece respirator and a surgical mask at various breathing conditions. Aerosol Science and Technology, 47(11), 1180-1187. https://doi.org/10.1080/02786826.2013.829209 
He, X., Reponen, T., McKay, R. T., \& Grinshpun, S. A. (2013b). Effect of Particle Size on the Performance of an N95 Filtering Facepiece Respirator and a Surgical Mask at Various Breathing Conditions. Aerosol Science and Technology, 47(11), 1180-1187. https://doi.org/10.1080/02786826.2013.829209

He, X., Son, S. Y., James, K., Yermakov, M., Reponen, T., McKay, R. T., \& Grinshpun, S. A. (2013). Exploring a novel ultrafine particle counter for utilization in respiratory protection studies. Journal of Occupational and Environmental Hygiene, 10(4). https://doi.org/10.1080/15459624.2013.766555

Kim, K. E., Cho, D., \& Park, H. J. (2016). Air pollution and skin diseases: Adverse effects of airborne particulate matter on various skin diseases. Life Sciences, 3-36. https://doi.org/10.1016/j.1fs.2016.03.039

Kulkarni, P., Baron, P., \& Willeke, K. (2011). Aerosol Measurement: Principles, Techniques and Apllications. In Aerosol Measurement. https://doi.org/10.1002/9781118001684

Myer, W., \& Allender, J. (1988). Myers etal Causes of In-facepiece Sampling Bias II-Full Facepiece Respirators Ann Occ Hyg 1988.pdf. Annals of Occupational Hygiene, 32(3), $361-372$.

Myers, W., Allender, J., Iskander, W., \& Stanley, C. (1988). Myers etal Causes of In-facepiece Sampling Bias I-Half Facepiece Respirators Ann Occ Hyg 1988.pdf. Ann. of Occupational Hygiene, 32(3), 345-359.

Myers, W., Allender, J., Ralph, P., \& Terrence, S. (1986). Parameters that bias the measurement of airborne concentration within a respirator. Journal of Safety Research, Vol. 17, pp. 106114. https://doi.org/10.1016/0022-4375(86)90060-5 
Oestenstad+, R., Dillion, K., \& Perkins, L. (1990). Distribution of faceseal leak sites on a half mask respirator and their association with facial dimensions. American Industrial Hygiene Association Journal, 51(5), 285-290.

Oestenstad+, R., Perkins, J., \& Rose, V. (1990). Identification of Faceseal Leak Sites on a HalfMask Respirator. American Industrial Hygiene Association Journal, 51(5), 280-284.

OSHA. (2019). 1910.134 App A - Fit Testing Procedures (Mandatory). | Occupational Safety and Health Administration. Retrieved September 1, 2020, from OSHA Fit Testing Procedures website: https://www.osha.gov/lawsregs/regulations/standardnumber/1910/1910.134AppA

OSHA. (2020a). 1910.134 - Respiratory Protection. | Occupational Safety and Health Administration. Retrieved September 1, 2020, from OSHA Regulations and Standards website: https://www.osha.gov/laws-regs/regulations/standardnumber/1910/1910.134

OSHA. (2020b). Respirator Fit Testing | Occupational Safety and Health Administration. Retrieved September 1, 2020, from OSHA: Respiratory Protection - Fit Testing Transcript. website: https://www.osha.gov/video/respiratory_protection/fittesting_transcript.html

OSHA. (2020c). Respirator Types | Occupational Safety and Health Administration. Retrieved September 1, 2020, from Transcript for the OSHA Training Video on Respirator Types website: https://www.osha.gov/video/respiratory_protection/resptypes_transcript.html

Pashin, Y. V, \& Bakhitova, L. M. (1979). Mutagenic and carcinogenic properties of polycyclic aromatic hydrocarbons. Environmental Health Perspectives, 30, 185-189.

Rengasamy, S., \& Eimer, B. C. (2011). Total inward leakage of nanoparticles through filtering 
facepiece respirators. Annals of Occupational Hygiene, 55(3), 253-263.

https://doi.org/10.1093/annhyg/meq096

Rengasamy, S., \& Eimer, B. C. (2012). Nanoparticle penetration through filter media and leakage through face seal interface of n95 filtering facepiece respirators. Annals of Occupational Hygiene, 56(5), 568-580. https://doi.org/10.1093/annhyg/mer122

Rengasamy, S., Eimer, B. C., \& Szalajda, J. (2014). A quantitative assessment of the total inward leakage of $\mathrm{NaCl}$ aerosol representing submicron-size bioaerosol through $\mathrm{N} 95$ filtering facepiece respirators and surgical masks. Journal of Occupational and Environmental Hygiene, 11(6), 388-396. https://doi.org/10.1080/15459624.2013.866715

Valero, D. (2014). Air Pollutant Hazards 7.1. In Fundamentals of Air Pollution (Fifth Edition) (pp. 197-214). Retrieved from http://dx.doi.org/10.1016/B978-0-12-401733-7.00007-4 197

Vo, E., Zhuang, Z., Horvatin, M., Liu, Y., He, X., \& Rengasamy, S. (2015). Respirator Performance against Nanoparticles under Simulated Workplace Activities. Annals of Occupational Hygiene, 59(8), 1012-1021. https://doi.org/10.1093/annhyg/mev042

Wu, B. (2018). Ensuring Respiratory Protection through Respirator Fit Testing and Real-Time Monitoring. Retrieved from http://rave.ohiolink.edu/etdc/view?acc_num=ucin1535374058309808 